\title{
Zimbabwe: land of hope and ...
}

\author{
J S BINGHAM \\ From James Pringle House, Middlesex Hospital, London
}

SUMMARY Control of the sexually transmitted diseases (STDs) is one of the immense medical $\overrightarrow{0}$ problems facing Zimbabwe. The recent war has seriously disrupted the medical services, which $\overrightarrow{\vec{\epsilon}}$ used to be one of the best in Africa. Health care facilities for the STDs are limited, but the $\mathscr{\omega}^{\omega}$ enthusiasm and determination of the medical and allied professions-together with the potential $\stackrel{\omega}{=}$. wealth of the country-should lead to a steady improvement.

\section{Introduction}

Zimbabwe is a land-locked country approximately the size of France. It is situated to the north of South Africa in the centre of southern Africa. Its population consists of some six million blacks and just under half a million whites. There is a small number of Asians.

\section{HISTORY}

The modern history of the country began in 1889 , when the Charter to the British South Africa Company to exploit the Rudd Concession-the arrangement by which Cecil Rhodes acquired the mineral rights to the area-received the Royal Assent. The following year the "Pioneer Column" reached the foot of Harare Hill, now Salisbury Kopje, the Union Jack was hoisted, and Salisbury was founded. Further treks from South Africa increased the white population and progress was rapid. The colony became self-governing, under the Crown, in 1923. The subsequent history of the country was substantially influenced by a local surgeon, Mr G M Huggins, who was elected Prime Minister in 1933 and who remained in power to lead the country, as Sir Godfrey Huggins, for the next 20 years until 1953. Subsequently, as Lord Malvern, he was Prime Minister of the Federation of Rhodesia and Nyasaland, of which Zimbabwe-then Southern Rhodesia-was part. The Federation was disbanded in 1963 leading to the independence of Northern Rhodesia as Zambia and of Nyasaland as Malawi. The dispute between the Southern Rhodesian and British governments over the future of the country

Address for reprints: Dr J S Bingham, James Pringle House, Middlesex Hospital, London W1

Accepted for publication 11 September 1980 ended with the unilateral declaration of indepen $-\stackrel{\infty}{\circ}$ dence by $\mathrm{Mr}$ Ian Smith in 1965. The frustrated political aspirations of the black majority led to the $\vec{c}$ recent bitter war and to independence finally being granted by Britain in April 1980.

\section{ECONOMY}

The country supports itself by agriculture, light industry, and mining. Irrigation schemes have allowed extensive farming and the country now produces all the staple foods in addition to much for export. There is modest mineral wealth with the mining of copper, gold, chrome, nickel, and other metals. Coal and asbestos are also produced. United Nations trade sanctions forced extensive expansion of light industry, which is now a boon to the new country.

\section{Medical Services}

With all this progress there has naturally been $a \subseteq$ demand for medical care. Hospitals were built in all the main towns of Zimbabwe. Rural hospitals were응 also opened to serve rural communities, and there are $D$ a number of mission hospitals throughout the country. The two major cities, Salisbury and N Bulawayo, have a series of municipal clinics, where primary health care is provided to a high standard 0 and where more complicated cases are referred on tow the main hospitals. There are several hospitals in Salisbury, the newest and largest of which is theo magnificent Andrew Fleming Hospital; this is adjacent to and associated with the Godfrey Huggins? School of Medicine, the country's only medical school. This had orginally been associated with the Birmingham Medical School, in England, but since 1974 has been conferring its own degrees through the ${ }_{0}^{\mathbb{Q}}$ University of Rhodesia (now Zimbabwe). 
Health care is provided on a two-tier system. The higher income groups, until recently mainly whites and Asians, pay income-related contributions to medical aid societies and this entitles them to private medical care. The rest of the community-the vast majority-pay no contributions but attend the various government facilities, where a small charge is made for outpatient and inpatient care, if they can afford it. No-one is turned away because of their inability to pay. It is likely that the new government will alter this system in keeping with its general policy.

As in other parts of Africa, medically qualified doctors are not always consulted first during an illness. Advice is often sought initially from a "traditional" doctor-the Nganga. It is probably futile to try to prevent patients from consulting these people and is almost certainly better to try to educate them and integrate them in the overall system. Some progress in this direction has been made in the field of midwifery, and the new government has declared aspirations in this direction.

The medical problems facing the country are immense. The recent political chaos and war have probably set the country back 30 years in terms of human and animal health. ${ }^{1}$ The war has resulted in the closure of many rural facilities and people have had to travel to the towns and cities for medical care. Salisbury, because of its fortunate geographical situation, has not been directly affected by the war, but indirectly the influx of refugees from the country areas into the city has posed problems for the housing and public health authorities.

\section{SEXUALLY TRANSMITTED DISEASES}

The sexually transmitted diseases (STDs) are rife at present. The war, with its consequent disruption of life leading to overcrowding in the towns and cities and the breaking up of families, has no doubt contributed to this, as it has elsewhere in the past. The control of the STDs is seen as one of the health care challenges facing the country at present, along with the problem of deaths in those under 5 years of age and the need to improve the obstetric services. There has been comment about the venereal diseases in the literature concerning southern Africa for some time. Between 1802 and 1806 Lichenstein found no evidence of syphilis among the Xhosas. Livingstone, travelling in Bechuanaland in 1857, wrote that syphilis was unable to maintain itself in any permanent form in persons of pure African blood anywhere in the centre of the country. However, Warren, during his expedition to Bechuanaland in 1885, found "the natives to be badly infected." The district surgeon, Dr Bedford, in 1887 found more than half of the 5529 "natives" examined by him to be syphilitic, and Mitchell, in 1917, reported a chief in the Northern Transvaal who was so impressed by the efficacy of the smallpox vaccination that he caused some $300-400$ members of his tribe to be inoculated with needles from a case of infectious syphilis; the results are not recorded.

After the second world war the Southern Rhodesian government recognised that the venereal diseases constituted a major health problem at the time. They invited Dr R R Willcox to carry out a comprehensive survey of the problem. He reported in $1949^{2}$ and made various recommendations, which included the institution of basic diagnostic techniques. Sadly, very little progress in this field has been made since that time. Interestingly in his report ${ }^{2}$ he did describe for the first time a form of endemic syphilis in the southern part of the country, known as njovera. This was said to be similar to bejel found in Iraq.

Today the two commonest infections are gonorrhoea and chancroid. Chancroid is the commonest cause of genital ulceration followed by syphilis; lymphogranuloma venereum is also frequently seen. Granuloma inguinale is less common and herpes genitalis is now being recognised more often. Nonspecific infection is infrequently diagnosed. Syphilis is seen in all its stages, although the later manifestations are rare. Inquiry in Salisbury indicated that the term, njovera, is now not thought of as a separate entity but rather as a local pseudonym for syphilis.

Patients who consider that they might have a venereal disease can be seen at virtually any medical facility in the country. Most units, however, do not have access to laboratory facilities. In Salisbury four of the municipal clinics have male orderlies trained in diagnosis and treatment; most cases are seen at two of these, the Bank Street Clinic and the Medical Examination Centre. Neither clinic is reserved exclusively for sexually transmitted diseases, the former being a primary care clinic and the latter a screening station for tuberculosis. They are, however, the only centres where figures are kept. The impression is that there is a low incidence of sexually transmitted diseases among women in general, and this view is supported by the small attendances of women at treatment facilities. The vast majority of men say that they paid money when they acquired their infection and it would seem that the volume of disease in men is maintained by a relatively small pool of women. ${ }^{3}$

The situation is improving. A venereologist has been appointed in Salisbury and medical students are receiving teaching in the subject. It is hoped to convert a municipal clinic in the centre of the capital for use exclusively in the treatment of sexually transmitted diseases. It is essential also to improve the 
diagnostic facilities available which will, apart from equipment, necessarily entail an increase in the number of staff. $\beta$-lactamase-producing strains of the gonococcus have not as yet been identified. A more regular surveillance of the sensitivities of the local strains of the gonococcus than is at present undertaken would be useful; culture as an aid to diagnosis is the exception rather than the rule.

\section{The Future}

Before the recent war Zimbabwe had one of the best medical services in Africa; these now have to be rebuilt. The visitor to the country is aware of the great enthusiasm of the medical and allied professions and of their determination to overcome the

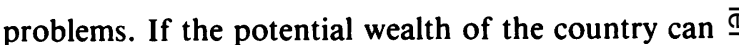
be realised then the future could be exceptional.

I am grateful to Professor I McL Brown for providing me with historical data on the presence of syphilis in Zimbabwe.

References

1. Davies JCA. Annual Report of the City Health Department, Salisbury, 1978; 1 .

2. Willcox RR. A Venereal Diseases Survey of the African in Southern Rhodesia. Salisbury: Southern Rhodesian Government, 1949.

3. Davies JCA. Annual Report of the City Health Department, Salisbury, 1979;52-3. 